Çukurova Üniversitesi Mühendislik Mimarlık Fakültesi Dergisi, 34(3), ss. 123-129, Eylül 2019

Çukurova University Journal of the Faculty of Engineering and Architecture, 34(3), pp. 123-129, September 2019

\title{
Süt Endüstrisi Atıksularının Yukarı Akışlı Anaerobik/Aktif Çamur Reaktörleri ile Arıtılabilirlik Çalışması
}

\author{
Şevket TULUN"1 \\ ${ }^{1}$ Aksaray Üniversitesi, Mühendislik Fakültesi, Çevre Mühendisliği Bölümü, Aksaray
}

$\ddot{\mathbf{O} z}$

Geliş tarihi: 19.03.2019 Kabul tarihi: 30.09.2019

$\mathrm{Bu}$ çalışmada süt endüstrisi atıksularını yukarı akışlı çamur yataklı anaerobik reaktör (UASB) ve aktif çamur reaktör sistemleri kullanılarak altı aylık süre boyunca arıtım verimleri incelenmiştir. Arıtılabilirlik çalışmalarında atıksular önce UASB reaktöre sonra aktif çamur reaktör sistemlerine verilmiştir. Her bir reaktör ve sistemden çıkan sular için 5 günlük biyokimyasal oksijen ihtiyacı (BOİ ${ }_{5}$ ), toplam organik karbon (TOK) ve askıda katı madde (AKM) parametreleri incelenmiş̧tir. Çıkış atıksuyunda $\mathrm{BOI}_{5}$, TOK ve AKM parametrelerinde elde edilen arıtma verimleri sırasıly $\% 99,33, \% 94,55$ ve $\% 89,23$ olduğu tespit edilmiştir. Elde edilen sonuçlar değerlendirildiğinde süt endüstrisi atıksularının UASB ve aktif çamur reaktörleri ile etkin bir şekilde arttılabileceği belirlenmiştir.

Anahtar Kelimeler: Süt endüstrisi atıksuları, Yukarı akışlı çamur yataklı anaerobik reaktör, Aktif çamur reaktör

\section{Treatment of Dairy Industry Wastewater Using Up-Flow Anaerobic Sludge Blanket/Activated Sludge Reactors}

\begin{abstract}
In this study, the treatment efficiencies of the dairy wastewater were investigated by using up-flow anaerobic sludge blanket reactor (UASB) and activated sludge reactor systems for six months. In treatability studies, wastewaters were first given to the UASB reactor and then to activated sludge reactor systems. 5day biochemical oxygen demand $\left(\mathrm{BOD}_{5}\right)$, total organic carbon (TOC) and suspended solids (SS) removal efficiencies were investigated for each reactor and system effluent. The effluent yields obtained from $\mathrm{BOD}_{5}$, TOC and SS parameters were $99.33 \%, 94.55 \%$ and $89.23 \%$, respectively. When the results were evaluated, it was determined that the wastewater from the dairy industry could be effectively treated with UASB and activated sludge reactors.
\end{abstract}

Keywords: Dairy industry wastewater, Up-flow anaerobic sludge blanket reactor, Activated sludge reactor

\footnotetext{
*Sorumlu (Başlıca) yazar (Corresponding author): Şevket TULUN, sevkettulun@gmail.com
} 


\section{GíRiș}

Endüstrilerde üretilen atıksu miktarı su kullanımının yanı sıra sanayi tipine bağlı olarak değişkenlik gösterir. Birçok ülkede süt ve süt ürünlerine olan talebin sürekli artması süt endüstrisinin hızlı bir şekilde büyümesine neden olmuştur [1]. Süt endüstrisi tüm dünyadaki en büyük sanayilerinden biridir [2]. Süt endüstrisi birçok ülkede gıda işleme atıksularının büyük bir kısmının kaynağı olarak kabul edilir. Sular; temizlik, sanitasyon, 1sitma, soğutma ve zemin temizliği dahil olmak süt endüstrisinde tüm adımlarında kullanılır $[3,4]$. Üretilen atıksu miktarı işlenen $1 \mathrm{~L}$ süt başına $0,2-10 \mathrm{~L}$ aralığında olduğu tahmin edilmektedir [5]. Süt endüstrisinde, özellikle laktoz, protein ve sütten oluşan yağlar olmak üzere farklı özellikte atıksular oluşur. Bu atıksular arıtım yapılmadan deşarj edildiğinde hem ötrifikasyona hem de nütrient kaybına neden olur [6,7]. Amerika Birleşik Devletleri (ABD) gibi pek çok ülkenin kanunlarında atıksularda bulunan besinlerin deşarjına yönelik kısıtlayıcı önlemler almıştır [8].

Bu nedenle süt atıksuları atık su deşarj standartlarını (AB Direktifi 2000/60/EC) karşılaması gerekmektedir [9]. Süt endüstrisi atıksuları elde edilecek ürünün türüne bağlı olarak, kullanılacak ekipman ve süreçlere bağlı olarak atıksu özelliği değişlik gösterir [10,11]. Bu nedenle uygun bir arıtma tesisi tasarlanması amacıyla süt endüstrisi için özel koşulların göz önünde bulundurulması gerekmektedir [10,12]. Atıksuları yüksek besin maddeleri ve organik maddeler ile karakterize edilir $[13,14]$. pH'1 son ürüne bağlı olmakla beraber 6,6-12,2 aralığında değişebilir [15].

Süt endüstrisi atıksuları aerobik teknolojiler ile arıtımı sınırlıdır. Sınırlı olmasının temel nedeni, yüksek organik yükleri, oksijen tedariki için fazla enerji gereksinimleri, oksijen aktarımındaki sorunlar, fazla çamur oluşumu ve oluşan çamurun katılaştırmasında ve kalınlaşmasındaki zorluklardır $[16,17]$. Ancak biyolojik arıtım yöntemleri dezavantajlarına rağmen kullanımı yaygındır [18].

Biyolojik arıtım yöntemlerinin yanı sıra membran [19], adsorpsiyon [20], koagülasyon-flokülasyon
[21] ve elektrokimyasal [22] arıtımları içeren fiziksel-kimyasal arıtımlar kullanılmaktadır [23]. $\mathrm{Bu}$ yöntemlerin en önemli dezavantajları arasında ilave reaktif maliyeti ve düşük organik madde giderimi bulunmaktadır. Havalandırmalı lagünler su kalitesinde dalgalanmalara ve fazla alan ihtiyacından, anaerobik lagünler ise $\mathrm{H}_{2} \mathrm{~S}$ gibi kötü koku oluşturmasından [24] dolayı her sistemin ayrı ayrı kullanılması fizibil olmamaktadır.

Süt endüstrisi atıksularının arıtımında en çok kullanılan yöntemler biyolojik arıtım yöntemler olması ve yüksek verimlerde giderim elde edilmesinin yanında yukarıda bahsedilen dezavanatajlarını azaltıcı önlemler alınması gerekmektedir.

Yukarı akışlı çamur yataklı anaerobik reaktörler (UASB) yaklaşık 20 yıldır süt endüstrisi atıksularının arıtımında başarılı bir şekilde uygulanmaktadır. Geçmiş yıllarda süt endüstrisi atıksuları ile birçok çalışma yapılma yapılmıştır. Peynir atıksularının laboratuvar ölçekli UASB reaktörleri ile 6 günlük hidrolik bekletme süresi sonucunda giriş kimyasal oksijen ihtiyacı (KOİ) değerine bağlı olarak \%85 ile \%99 arasında giderim verimleri elde edildiği rapor edilmiştir [25].

Süt ve evsel atıksuların kombinasyonundan oluşana atıksuların arıtılması için anaerobik sistem ve aerobik sistem birlikte kullanılmıştır. 26 saatlik hidrolik bekletme süresi (24 saati yukarı akışlı çamur yataklı anaerobik reaktör, 2 saat aktif çamur için) sonunda toplam KOİ değerinin \%98,9, biyokimyasal oksijen ihtiyacı (BOİ $)$ değerinin \%99,6’lık kısmı giderilmiştir [26]. Aerobik biyoreaktörler süt endüstrisi atıksuları için KOİ, toplam fosfor (TP) ve toplam azot (TN) konsantrasyonlarının azaltımına yönelik bir ön işlemdir [27].

$\mathrm{Bu}$ çalışma da süt endüstrisinden temin edilen atıksuların UASB reaktör ve aktif çamur reaktörlerinin bir araya getirilmesi sonucu oluşan kombine sistem kullanılarak süt endüstrisi atıksularının toplam organik karbon (TOK), BOİ ve askıda katı madde (AKM) giderim verimleri incelenmiştir. 


\section{MATERYAL VE METOT}

\subsection{Materyal}

Çalışmada kullanılan atıksu örneği Aksaray İli’nde faaliyet gösteren süt ve süt ürünleri üretimi yapan bir fabrikadan haftalık olarak alınmıştır. Alınan örnekler $+4{ }^{\circ} \mathrm{C}$ 'de saklanarak 20 L'lik besleme tanklarına konulmuş ve tasarlanan arıtma sistemine pompa yardımıyla iletilmiştir. Kullanılan atıksuyun karakterizasyonu Çizelge 1'de gösterilmiştir.

Çizelge 1. Ham atıksuyun karakterizasyonu

\begin{tabular}{|l|c|c|c|c|}
\hline Parametre & $\begin{array}{c}\text { Ölçüm } \\
\text { Sayısı } \\
(\mathbf{n})\end{array}$ & Birim & $\begin{array}{c}\text { Ortalama } \\
\text { Sonuç } \\
\text { (Xort) }\end{array}$ & $\begin{array}{c}\text { Standart } \\
\text { Sapma } \\
\text { Değeri } \\
(\boldsymbol{\sigma})\end{array}$ \\
\hline $\mathrm{pH}$ & 24 & - & 6,76 & 0,27 \\
\hline Sicaklık & 24 & ${ }^{\circ} \mathrm{C}$ & 25,1 & 0,2 \\
\hline$\dot{I ̇ l e t k e n l i k ~}_{\mathrm{BOI}}$ & 24 & $\mu \mathrm{s} / \mathrm{cm}$ & 3950 & 25 \\
\hline $\mathrm{AKM}$ & 24 & $\mathrm{mg} / \mathrm{L}$ & 2363 & 103 \\
\hline TOK & 24 & $\mathrm{mg} / \mathrm{L}$ & 3310 & 285 \\
\hline
\end{tabular}

Laboratuvar ortam $125 \pm 1{ }^{\circ} \mathrm{C}$ 'de klima yardımıla sabit tutulmuştur. UASB reaktörün beslemesi, otomatik ayarlanabilir pompa yardımı ile $20 \mathrm{~L}$ besleme tankında bulunan atıksu ile sağlanmıștır. UASB reaktör paslanmaz çelikten yapılmış, $0,06 \mathrm{~m}$ çapında $1 \mathrm{~m}$ yüksekliğinde, $2 \mathrm{~L}$ hacim sahip olup kullanılabilir hacmi 1,75 L'dir. USAB reaktörden çıkan atıksular $0,07 \times 0,18 \times 0,3 \mathrm{~m}$ boyutlarında, 1,5 L hacmi havalandırma bölmesinden, 0,65 L çökelme bölmesinden oluşan aktif çamur reaktörüne verilmiștir. Havalandırma bölmesi ile çökelme bölgesi delikli bir plaka yardımıyla ayrılmıştır. Aktif çamur reaktörü, 8 saat hidrolik alıkonma süresi ve 18 gün çamur alıkonma süresinden işletilmiştir. Reaktörde havalandırma havzasında yeterli oksijen ( $>2 \mathrm{mg} / \mathrm{L}$ ) hava pompası kullanılarak oluşturulmuştur. Çökelmiş çamurun havalandırma havuzuna geçişi çamur geri dönüşüm oranı (r) 1 sabitlenmesi şartıyla tabanda bulunan $2 \mathrm{~cm}$ açıklıktan sağlanmıştır. Reaktör ortalama $1600 \mathrm{mg} \quad \mathrm{MLVSS} / \mathrm{L}$ mikroorganizma konsantrasyonda işletilmiştir. Arıtılabilirlik çalışmalarının yapıldığı deney düzeneği Şekil 1'de gösterilmiştir.

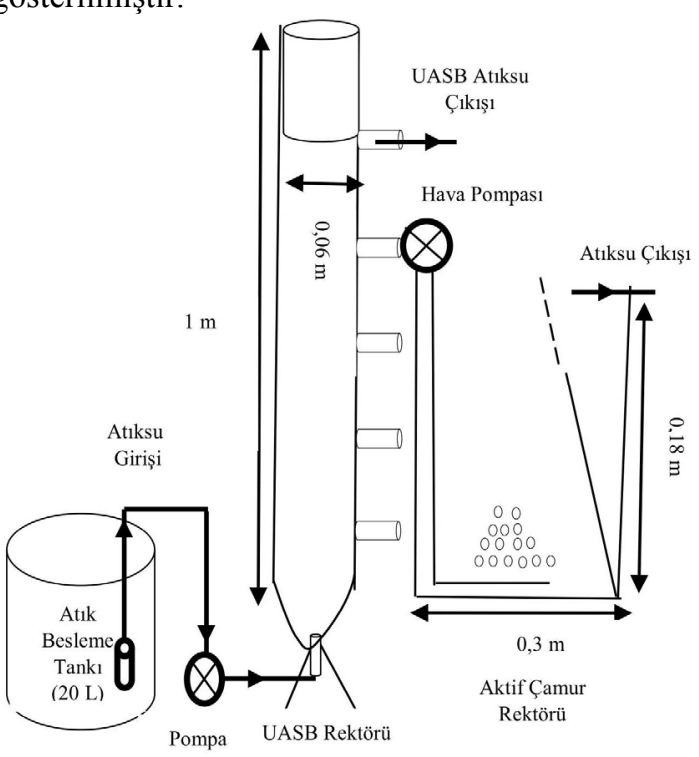

Şekil 1. Deney düzeneğinin şematik gösterimi

\subsection{Analiz Yöntemleri}

pH, elektriksel iletkenlik ve sıcaklık ölçümleri dijital iyon analizi yapan (Hach, HQ440d) cihazı kullanılmıştır. Atıksu numunelerinde TOK ile toplam azot (TA) miktarı Shimadzu marka ve TOCVCPN/TNM-1 modelli TOK-TA cihazıyla belirlenmiştir. 5 günlük biyolojik oksijen ihtiyacı $\left(\mathrm{BOI}_{5}\right)$ oksitop (WTW) ölçüm yöntemine göre yapılmıştır [31]. Atıksu numunelerindeki AKM $0,45 \mu \mathrm{m}$ gözenek çapındaki filtrelerden süzülerek gravimetrik olarak tespit edilmiştir. Tüm deneysel çalışmalar 3 tekrarlı ve doğrulamalı olarak yapılmıştır. Sonuçlar arasında \%10'luk fark oluşması durumunda çalışmalar tekrarlanmıştır. Çalışmalarda kullanılan tüm kimyasallar \%99,9 analitik saflıktadır.

\section{BULGULAR}

\subsection{Günlük Biyokimyasal Oksijen İhtiyacı Giderim Verimleri}

Süt endüstrisi atıksularının önce UASB reaktörlerine daha sonra aktif çamur reaktörüne 
verilmesi sonucu her bir reaktör çıkışında elde edilen $\mathrm{BOI}_{5}$ giderim verimleri ile sistemin tamamında elde edilen giderim verimleri Şekil 2'de verilmiştir.

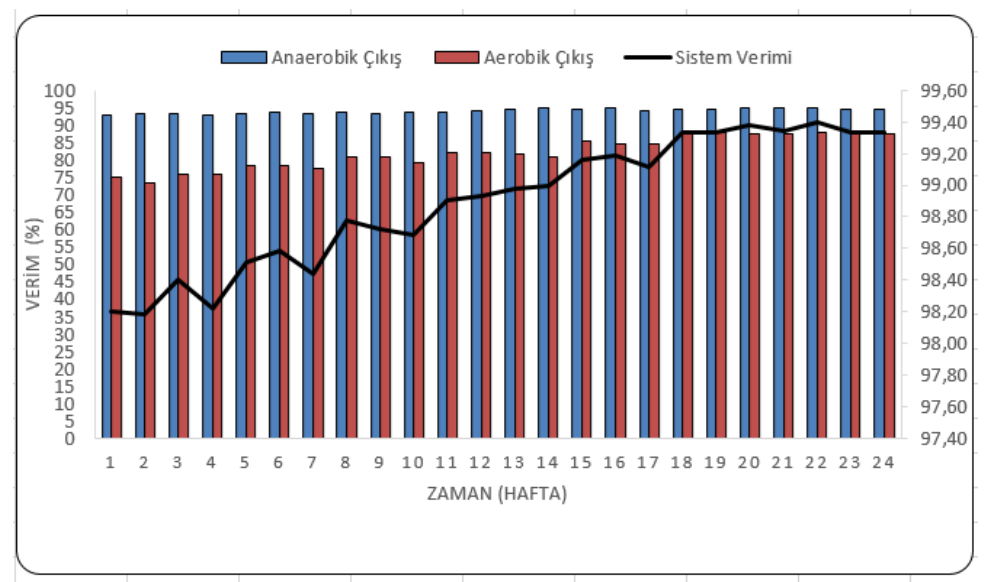

Şekil 2. BOİ $_{5}$ giderim verimleri

Şekil 2'de görüldüğü gibi UASB reaktöre de $\mathrm{BOI}_{5}$ giderim verimleri $\% 92,00$ 'in üzerindedir. Ham atısuyun $\mathrm{BOI}_{5} \quad$ değeri $2363 \pm 103 \quad \mathrm{mg} / \mathrm{L}$ seviyelerindeyken 24 haftalık işletme süresi sonunda UASB reaktör çıkışında $120 \mathrm{mg} / \mathrm{L}$ 'ye düşmüştür ve $\% 94,67^{\prime} l i k$ giderim verimi elde edilmiştir. UASB çıkış suyu aktif çamur reaktörüne verildiğinde belirlenen işletme süresi sonunda $\% 87,5^{\prime}$ lik arıtım verimi elde edilmiştir. Aktif çamur reaktörüne gelen organik yükün büyük bir kısmı UASB reaktöründe giderilmesinden dolayı aktif çamur reaktörüne gelen atıksuyun organik yükü azalmış ve buna bağlı olarak aktif çamur reaktöründe verim artmıştır. Sistemin genel giderim verimi ise \%99,33 olarak belirlenmiştir. İlk 17 hafta işletme sürelerinde giderim verimi kademeli olarak artmış daha sonraki işletme sürelerinde ise giderim verimlerinde fazla bir artış olmamıştır.

\subsection{Askıda Katı Madde Giderim Verimleri}

Benzer şartlar altında hem her bir reaktör çıkışlarında askıda katı madde giderimleri hem de sistem sonunda elde edilen giderim verimleri Şekil 3'de verilmiştir.

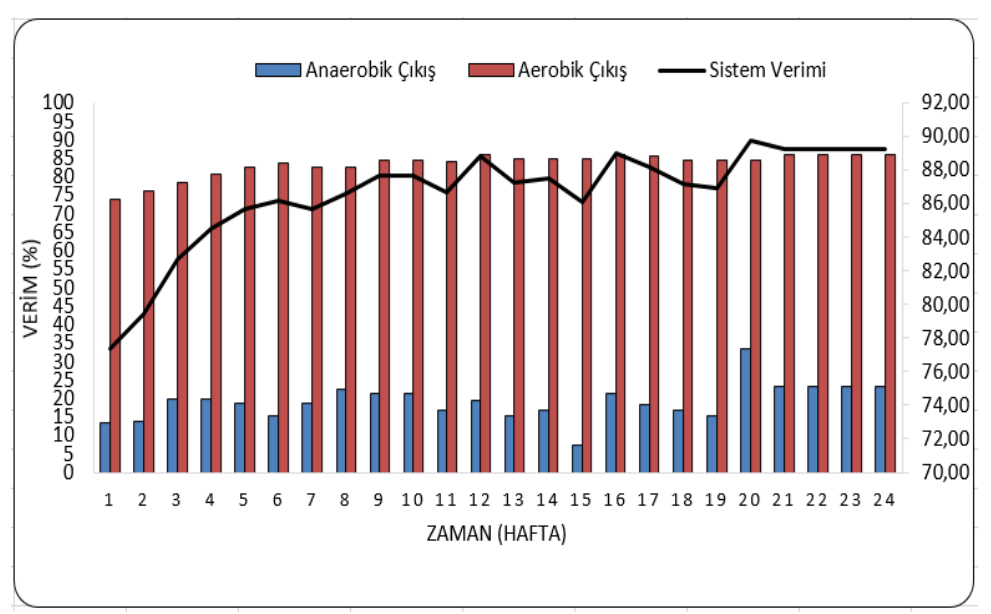

Şekil 3. AKM giderim verimleri 
UASB reaktör çıkışında AKM giderim verimleri en yüksek \%23,08 bulunmuştur. AKM giderim verimlerinin düşük olmasının ana nedeni UASB reaktörden katı madde kaçışıdır. Reaktör içerisinde çökelme özelliğindeki zayıf çamurlar reaktörden yıkanarak çıkmıştır. UASB reaktöründen çıkan atıksular aktif çamur sistemine verilmesi sonucu AKM giderim verimleri belirlenen işletme süresi sonunda \%86,00 olarak belirlenmiştir. Aktif çamur sisteminde yüksek verim elde edilmesi çökelme bölümünün verimliliğinin göstergesidir. Sisteminin genel AKM giderim verimi \%89,23 olduğu tespit edilmiştir.

\subsection{Toplam Organik Karbon Giderim Verimleri}

Laboratuvar şartlarında süt endüstrisi atıksularının toplam organik karbon (TOK) giderim verimlerine her bir reaktörün etkisi ve sistemin genel etkisi Şekil 4' te verilmiştir.

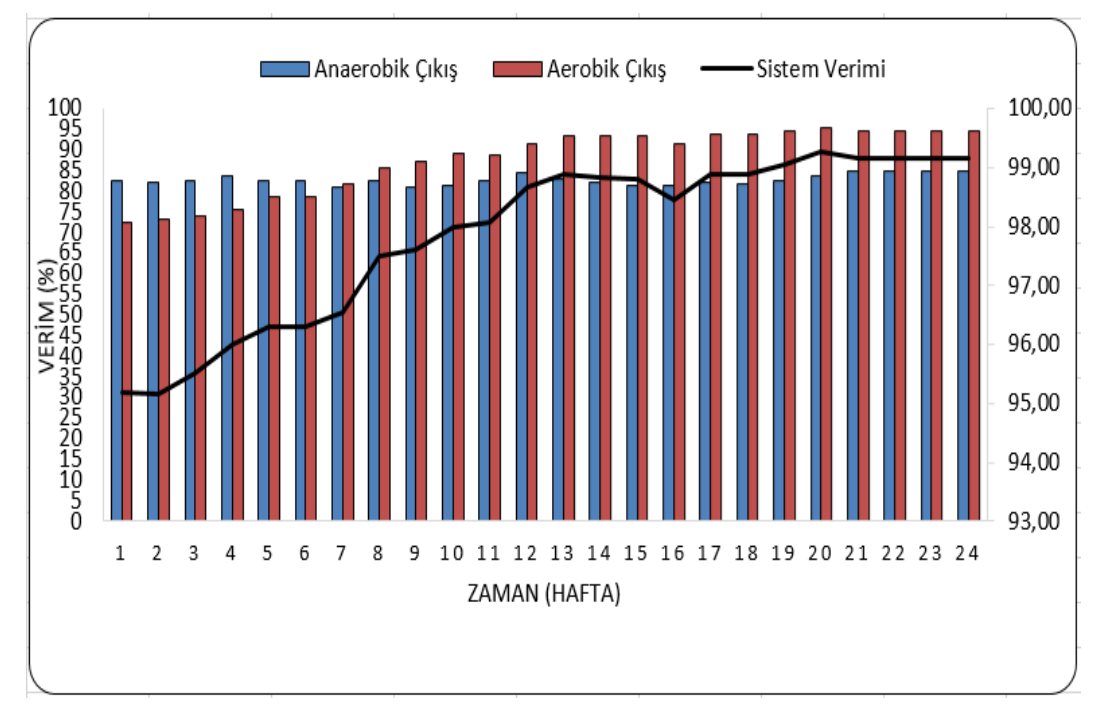

Şekil 4. TOK giderim verimleri

UASB reaktör çıkış suyunda TOK $220 \mathrm{mg} / \mathrm{L}$ ölçülmüştür. Yaklaşık \%84,83'lük giderim verimi sağlanmıştır. Giderim veriminin yüksek olması UASB reaktörü içerisinde bulunan çamur ile atıksu arasında optimum temas süresi sağlanmış olmasıdır. Yüksek organik madde konsantrasyonuna sahip süt endüstrisi atıksularının reaktör içerisindeki temas süresi arıtım verimi açısından önemlidir. UASB reaktörü çıkış suyunda organik yükü ciddi miktarda azalan atıksuyun aktif çamur reaktörü çıkış suyunda TOK $12 \mathrm{mg} / \mathrm{L}$ 'ye düşmüştür. Belirlenen işletme süresi sonunda sistem geneli giderim verimi \%94,55' dir.

\section{SONUÇLAR}

Birçok endüstriyel faaliyetlerde olduğu gibi süt endüstrisinde de üretimi yöntemine bağlı olarak farklı karakterizasyonlarına sahip atıksu oluşmaktadır. Oluşan atıksu genellikle yüksek organik madden, fazla miktarda yağdan ve katı maddelerden oluşur. Bu özelliğe sahip atıksuların arıtılması oldukça zordur. $\mathrm{Bu}$ çalışmada UASB reaktörü ile birlikte aktif çamur reaktöründen oluşan arıtma sisteminin KOİ, BOİ 5 ve AKM giderim verimleri hem reaktörler bazında hem de arıtma sistemi bazından ayrı ayrı incelenmiştir.

$\mathrm{BOI}_{5}$ ve TOK parametreleri belirlenen işletme süreleri sonunda UASB reaktör çıkış suyunda sırasıyla \%94,67, \%84,83 giderim verimleri elde edilmiştir. Giderim verimlerine bakılarak UASB reaktörün tek başına yeterli olduğu görülmektedir. AKM parametresi üzerinde UASB reaktörün etkisi oldukça az olduğu belirlenmiştir. Bunun temel nedeni reaktörden katı madde kaçışıdır. Aktif çamur reaktöründe AKM giderim verimi \%86,00 olarak 
belirlenmiştir. Çökelme haznesinden savaklanan suda yapılan bu analiz çökelmenin istenilen ölçüde gerçekleştirildiğinin göstergesidir.

Süt endüstrisi atıksularının arıtılabilirliğinin yapıldığı bu çalışmada sistem bütününde $\mathrm{BOI}_{5}$, TOK ve AKM parametrelerinde elde edilen aritma verimleri sirasiyla $\% 99,33, \% 94,55$ ve $\% 89,23$ olduğu belirlenmiștir. Süt endüstrisi atıksularının yapısında organik (karbon bazlı) maddeler bulunmaktadır. Organik yabancı maddeler çok çeşitli kaynaklardan gelebilir. $\mathrm{Bu}$ maddelerin biyolojik arıtımları neticesinde $\mathrm{BOI}_{5}$ verimleri daha yüksek olduğu belirlenmiştir. Atıksuyun yapısında plastik, yapıştırıcı bazlı organik ürünler bulunmasına bağlı olarak TOK giderim verimleri daha düşük olmuştur. Elde edilen sonuçlar değerlendirildiğinde süt endüstrisi atıksularının UASB ve aktif çamur reaktörleri ile etkin bir şekilde arıtılabileceği belirlenmiştir.

\section{KAYNAKLAR}

1. Adulkar, T.V., Rathod, V.K., 2014. Ultrasound Assisted Enzymatic Pre-treatment of High Fat Content Dairy Wastewater, Ultrasonics Sonochemistry 21, 1083-1089.

2. Sarkar, B., Chakrabarti, P.P., Vijaykumar, A., Kale, V., 2006. Wastewater Treatment in Dairy Industries-possibility of Reuse. Desalination 195(1-3), 1-306.

3. Farizoglu, B., Uzuner, S., 2011. The Investigation of Dairy Industry Wastewater Treatment in a Biological High Performance Membrane System. Biochemical Engineering Journal 57, 46-54.

4. Kumar, S., Gupta, N., Pakshirajan K., 2015. Simultaneous Lipid Production and Dairy Wastewater Treatment Using Rhodococcus Opacus in a Batch Bioreactor for Potential Biodiesel Application. Journal of Environmental Chemical Engineering 3, 1630-1636.

5. Perle, M., Kimchie, S., Shelef, G., 1995. Some Biochemical Aspects of the Anaerobic Degradation of Dairy Wastewater. Water Resources 29, 1549-1554.
6. Chen, Z., Luo, J., Chen, X., Hang X., Shen, F., Wan, Y., 2016. Fully Recycling Dairy Wastewater by an Integrated Isoelectric Precipitationnanofiltration-anaerobic Fermentation Process. Chemical Engineering Journal 283, 476-485.

7. Tocchi, C., Federici, E., Fidaati, L., Manzi, R., Vincigurerra, V., Petruccioli, M., 2012. Aerobic Treatment of Dairy Wastewater in an Industrial Three-reactor plant: Effect of Aeration Regime on Performances and on Protozoan and Bacterial Communities. Water Research 46, 3334-3344.

8. Vidal, G., Carvalho, A., Méndez, R., Lema, J.M., 2000. Influence of the Content in Fats and Proteins on the Anaerobic Biodegradability of Dairy Wastewaters. Bioresource Technology 74, 231-239.

9. Passeggi, M., López, I., Borzacconi, L., 2012. Modified UASB Reactor for Dairy İndustry Wastewater: Performance Indicators and Comparison with the Traditional Approach. Journal of Cleaner Production 26, 90-94.

10. Demirel, B., Yenigun, O., Onay, T. 2005. Anaerobic Treatment of Dairy Wastewaters: a Review. Process Biochemistry 40, 2583-259.

11. Perle, M., Kimchie, S., Shelef, G., 1995. Some Biochemical Aspects of the Anaerobic Degradation of Dairy Wastewater. Water Research 29(6), 1549-1554.

12. Andrade, L.H., Mendes, F.D.S., Espindola, J.C., Amaral, M.C.S., 2014. Nanofiltration as Tertiary Treatment for the Reuse of Dairy Wastewater Treated by Membrane Bioreactor. Separation and Purification Technology 126, 21-29.

13. Wolicka, D., 2008. Biotransformation of Phosphogypsum in Wastewaters from the Dairy Industry. Bioresource Technology 99, 5666-5672.

14. Bhatia, M., Goyal, D., 2014. Analyzing Remediation Potential of Wastewater Through Wetland Plants: A Review. Environmental Progress \&Sustainable Energy 33, 9-27.

15. Rilo, M.S., Coimbra, N.R., Villacorta, M.J., Otero, M., 2015. Treatment of Dairy Industry Wastewater by Oxygen Injection: Performance and Outlay Parameters from the Full Scale Implementation. Journal of Cleaner Production $86,15-23$. 
16. Turan, M., 2004. Influence of Filtration Conditions on the Performance of Nanofiltration and Reverse Osmosis Membranes in Dairy Wastewater Treatment. Desalination 170, 83-90.

17. Sarkar, B., Chakrabarti, P.P., Vijaykumar, A., Kale, V., 2006. Wastewater Treatment in Dairyindustries-possibility of Reuse. Desalination 195, 141-152.

18. Rivas, J., Prazeres, A.R., Carvalho, F., Beltran, F., 2010. Treatment of Cheese Whey Wastewater: Combined Coagulation-flocculation and Aerobic Biodegradation. Journal of Agricultural and Food Chemistry 58, 7871-7877.

19. Guven, G., Perendeci, A., Tanyolac, A., 2008. Electrochemical Treatment of Deproteinated Whey Wastewater and Optimization of Treatment Conditions with Responsesurface Methodology. Journal of Hazardous Materials $157,69-78$.

20. Karadag, D., Köroğlu, E.O., Ozkaya, B., Cakmakci, M., 2015. A Review on Anaerobic Biofilm Reactors for the Treatment of Dairy Industry Wastewater. Process Biochemistry 50, 262-271.

21. Kushwaha, P.J., Srivastava, C.V., Mall, D.I., 2011. An Overview of Various Technologies for the Treatment of Dairy Wastewaters. Critical Reviews in Food Science and Nutrition 51(5), 442-452.

22. Arvanitoyannis, S.I., Giakoundis, A., 2006. Current Strategies for Dairy Waste Management: A Review. Critical Reviews in Food Science and Nutrition, 46, 379-390.

23. Benaissa, F., Said, K.H., Mostefa, M.N., 2014. Optimization and Kinetic Modeling of Electrocoagulation Treatment of Dairy Wastewater. Desalination and Water Treatment, 5988-5994.

24. Hoseyni, M.S., Moradi, O., Tahmacebi, S., 2013. Removal of COD from Dairy Wastewater by MWCNTs: Kinetics and Thermodynamics. Fullerenes, Nanotubes, and Carbon Nanostructures 21, 794-803.

25. Akinbile, O.C., Yusoff, S.M., Zuki, A.A.Z., 2012. Landfill Leachate Treatment Using Subsurface Flow Constructed Wetland by Cyperus haspan. Waste Management 32, 1387-1393.
26. Yang, L., Tsai, Y.K., 2007. Treatment of Aged Landfill Leachate by Cascade Constructed Wetland Systems. Ecohydrology \& Hydrobiology 7(3-4), 353-359.

27. Healy, M.G., Rodgers M., Mulqueen, J., 2007. Treatment of Dairy Wastewater Using Constructed Wetlands and Intermittent Sand Filters. Bioresource Technology 98, 2268-2281. 28. Demirel, B., Yenigun, O., Onay, T.T., 2005. Anaerobic Treatment of Dairy Wastewaters: A Review. Process Biochemistry 40, 2583-2595.

29. Tawfik, A., Sobhey, M., Badawy, M., 2008. Treatment of a Combined Dairy and Domestic Wastewater in an Up-flow Anaerobic Sludge Blanket (UASB) Reactor Followed by Activated Sludge (AS System). Desalination 227, 167-177.

30. Heaven, W.M., Wild, K., Souza, D.D., Nahid, A., Tull, D., Watkins, M., Hannah, M., Nash, D., 2012. Physicochemical Properties and Trace Organic Compounds in a Dairy Processor's Aerobic Bioreactor. Bioresource Technology 124, 119-128.

31. APHA (American Public Health Association) (2012). American Water Works Association (AWWA) \& Water Environment Federation (WEF). Standard methods for the examination of water $\&$ wastewater, $22^{\text {nd }}$ ed. 
